\title{
Neural Signatures of Conscious Face Perception in an Inattentional Blindness Paradigm
}

\author{
Juliet P. Shafto and Michael A. Pitts \\ Department of Psychology, Reed College, Portland, Oregon 97202
}

Previous studies suggest that early stages of face-specific processing are performed preattentively and unconsciously, whereas conscious perception emerges with late-stage $(>300 \mathrm{~ms})$ neuronal activity. A conflicting view, however, posits that attention is necessary for face-specific processing and that early-to-mid latency neural responses $(\sim 100-300 \mathrm{~ms})$ correspond more closely with perceptual awareness. The current study capitalized on a recently developed method for manipulating attention and conscious perception during EEG recording (modified inattentional blindness paradigm) and used face stimuli that elicit a well known marker of early face processing, the N170 event-related potential (ERP). In Phase 1 of the experiment, subjects performed a demanding distracter task while line drawings of faces and matched control stimuli were presented in the center of their view. When queried, half of the subjects reported no awareness of the faces and were deemed inattentionally blind. In Phase 2, subjects performed the same distracter task, but now consciously perceived the face stimuli due to the intervening questioning. In Phase 3, subjects performed a discrimination task on the faces. Two primary contrasts were made: aware versus unaware (equally task irrelevant) and task-relevant versus task-irrelevant (equally aware). The N170 and a subsequent ERP component, the visual awareness negativity $(\sim 260-300 \mathrm{~ms})$, were absent during inattentional blindness and present in the aware conditions. The P3b (>300 ms) was absent for task-irrelevant faces, even when consciously perceived, and present only when the faces were task relevant. These results inform contemporary theories of conscious face perception in particular and visual attention and perceptual awareness in general.

Key words: attention; consciousness; faces; inattentional blindness; N170; VAN

\section{Introduction}

A promising approach for identifying neural signatures of conscious perception is to contrast conditions in which subjects are aware versus unaware of identical sensory information (Crick and Koch, 2003; Dehaene and Changeux, 2011). Various experimental paradigms are available for rendering stimuli invisible (e.g., backward masking, attentional blink, change blindness, interocular suppression; Kim and Blake, 2005; Axelrod et al., 2015). In many experiments, steps are taken to minimize confounding factors between aware and unaware conditions such as different mask onsets and unequal motor responses (Sergent et al., 2005; Fisch et al., 2009). Despite attempts to control for potential covariants, however, recent criticisms of the contrastive method have identified important distinctions between neural events immediately preceding/following conscious perception and neural activity underlying conscious perception itself (Aru et al., 2012a; de Graaf et al., 2012).

To allow for minimal contrasts between neural activity in aware versus unaware conditions, the inattentional blindness

\footnotetext{
Received Jan. 12, 2015; revised May 12, 2015; accepted June 20, 2015.

Author contributions: J.P.S. and M.A.P. designed research; J.P.S. performed research; J.P.S. analyzed data; J.P.S. and M.A.P. wrote the paper.

The authors declare no competing financial interests.

Correspondence should be addressed to Michael A. Pitts, Department of Psychology, Reed College, 3203 SE Woodstock Blvd, Portland, OR 97202. E-mail: mpitts@reed.edu.

DOI:10.1523/JNEUROSCI.0145-15.2015

Copyright $\odot 2015$ the authors $\quad 0270-6474 / 15 / 3510940-09 \$ 15.00 / 0$
}

paradigm (Mack and Rock, 1998; Simons and Chabris, 1999) was recently adapted for EEG (Pitts et al., 2012). In this modified paradigm, half of the subjects are inattentionally blind to the critical stimuli because their attention is focused on a distracter task despite extended stimulus durations (300 ms) and a large number of trials ( $>200$ critical trials). After being queried about their awareness of the stimuli, subjects perform the same distracter task in a second phase of the experiment, but now report full awareness of the previously unseen stimuli. Comparing brain activity between these two conditions permits "aware" versus "unaware" contrasts in which the critical stimuli are equally task irrelevant. In a third phase of the experiment, subjects are instructed to forego the distracter task and discriminate directly the critical stimuli, creating an "aware + task-relevant" condition that can be contrasted with the "aware" (task-irrelevant) condition.

The first study to use this paradigm used simple geometric shapes as critical stimuli and found evidence for unconscious shape processing $(\sim 180 \mathrm{~ms})$ during inattentional blindness (Pitts et al., 2012). This initial unconscious activity was followed by the "visual awareness negativity" (VAN; 300 ms; for review, see Railo et al., 2011) whenever subjects consciously perceived the shapes. Subsequent to the VAN, the selection negativity (SN), the $\mathrm{P} 3 \mathrm{~b}$, and induced gamma-band activity were evident, but only when the shapes were task relevant (Pitts et al., 2014a).

In the present study, the same inattentional blindness paradigm was used, but the critical stimuli were line drawings of faces. 
a Example Stimuli:
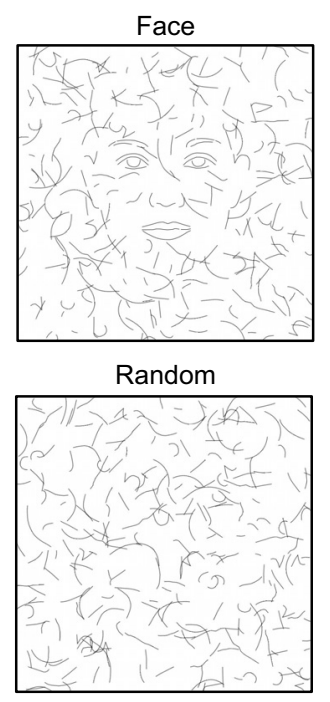

C Experiment Sequence:

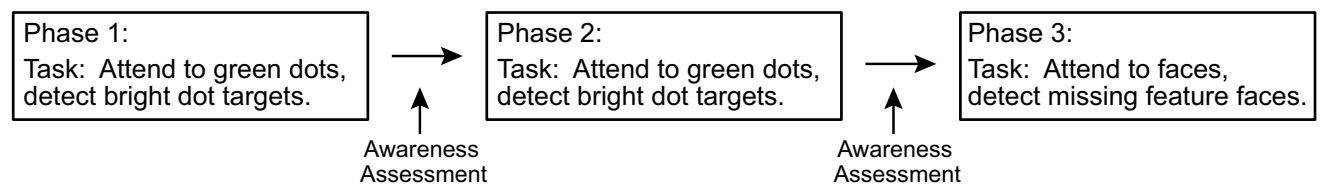

Figure 1. Stimuli and procedure. $\boldsymbol{a}$, Representative examples of face and random configuration stimuli. $\boldsymbol{b}, 0$ n each trial, a random configuration was presented for a variable interval (533- 600 $\mathrm{ms}$ ), followed by either a face or another random configuration for $300 \mathrm{~ms}$. This sequence was then repeated (the screen was never blank). ERPs were time locked to the line segment orientation/ location changes. Green dots overlaid on the line segments spun continuously around the three concentric rings. On $20 \%$ of trials, a brightened dot target appeared during the same 300 ms period as the faces and random configurations. c, During the first two phases of the experiment, subjects were instructed to press a button when they noticed one of the green dots brighten. During the third phase, participants were instructed to press a button when they noticed that a face that was missing a feature (eye, nose, or mouth; $20 \%$ of trials). Awareness assessments were conducted after each of the first two phases to determine whether subjects noticed the face stimuli.

This allowed for a targeted assessment of the presumed independence of early face-specific activity (marked by the N170) from attention and awareness (Furey et al., 2006; Sterzer et al., 2009; Harris et al., 2013). We predicted that the N170 component (Bentin et al., 1996) would be evident during inattentional blindness, the VAN would appear whenever subjects were aware of the faces, and the SN and P3b would only be present when the faces became relevant to the discrimination task.

\section{Materials and Methods}

Participants. Thirty-seven healthy volunteers between the ages of 18 and 26 participated in the experiment. All participants had normal or corrected-to-normal vision and no history of neurological conditions. Procedures were reviewed and approved by the Reed College Institutional Review Board in compliance with the Declaration of Helsinki.

Of the 37 participants, four were excluded due to an insufficient number of trials in at least one condition $(<100)$ after artifact rejection. An additional three subjects were excluded because the awareness assessment (see below) indicated that they had noticed the faces halfway through the first phase of the experiment. The 30 remaining participants (21 female, 29 right-handed, mean age 21) were included in the analysis.

Apparatus. The scalp EEG was recorded using a custom 96-channel electrode cap with $\mathrm{Ag} / \mathrm{AgCl}$ electrodes spaced equidistantly (EASYCAP). Electrode positions reported here refer to the nearest channels of the international 10-20 system. Electrode impedances were kept $<5 \mathrm{k} \Omega$. Electrical signals were band-pass filtered from 0.1 to $150 \mathrm{~Hz}$, amplified by 3 32-channel amplifiers (Brain Amp Standard; Brain Products), and digitized at $500 \mathrm{~Hz}$. Eye movements and blinks were monitored by left and right horizontal EOG channels and a vertical EOG channel under the left eye, respectively. An electrode positioned at $\mathrm{CPz}$ served as the reference during recording.

All experiments were conducted in a sound-attenuated, electrically shielded booth (Industrial Acoustics). Participants sat $\sim 75 \mathrm{~cm}$ from the $1920 \times 1200$ pixel display screen (Planar SA2311w23 LCD monitor). Responses were recorded with a Cedris button pad (Model RB-830). Stimuli were presented using the Presentation software package (Neurobehavioral Systems).

Stimuli. The face stimulus was based on an average female face used in Zhao et al. (2011). A line rendering of this face, composed of 36 individual short segments, was created manually in Inkscape (version 0.48.2) using the bezier curve tool. Each line segment that made up the face was copied seven times, randomly rotated, and pseudorandomly positioned within and outside of the face. Control stimuli (random configurations of lines) were created by rotating and repositioning the same lines. Example stimuli are provided in Figure 1.

The randomly oriented line segments in the face stimuli were distributed such that a small area around each feature (eyes, nose, and mouth) was left blank to avoid obscuring the facial features. Line segments in the random configurations were distributed such that the number of line segments appearing in the area of each facial feature matched the number of line segments composing that feature in the face stimuli. All stimuli occupied $9.5^{\circ}$ of visual angle horizontally and vertically. For face stimuli, the lines forming the face were presented in the center of the display, spanning $5.4^{\circ}$ of visual angle horizontally and vertically. Fifty percent of the stimuli contained faces and $50 \%$ were random control configurations (720 total stimuli; 360 faces, 360 random). Of the 360 face stimuli, 144 (20\% of the total stimuli) contained a missing feature (equally distributed between left eye, right eye, nose, and mouth) and 216 (30\% of the 
total stimuli) were intact faces. The missing feature faces would serve as the targets in the third phase of the experiment (see procedure below). All EEG/ERP comparisons were based on intact face stimuli and random control stimuli.

Each stimulus was presented for $300 \mathrm{~ms}$, separated by an interstimulus interval (ISI) of 533, 567, or $600 \mathrm{~ms}$ (jittered randomly). During the ISI additional random configurations of line segments were presented. Therefore, the screen was never blank and ERPs were time locked to line segment orientation/location changes. Other than the lines forming the face, all other line segments were oriented randomly and positioned to form 720 distinct stimuli and 720 distinct random ISI configurations. No stimulus or ISI configuration was repeated within each phase of the experiment. The same 720 stimuli and 720 ISI configurations were repeated (in randomized order) in each of the three phases of the experiment. The randomization of line segment orientations and locations was achieved using Processing software (version 2.0b3).

The distracter stimuli consisted of three concentric green rings (largest $6.5^{\circ}$, middle $4.5^{\circ}$, smallest $2.5^{\circ}$ ), each containing four small green dots spaced equidistantly. The dots were smallest on the innermost ring $\left(0.32^{\circ}\right)$, larger on the middle ring $\left(0.41^{\circ}\right)$, and largest on the outermost ring $\left(0.52^{\circ}\right)$. Throughout the experiment, the dots rotated along the rings at a rate of $52 \%$. The direction of rotation alternated between clockwise and counterclockwise across successive blocks of trials (every $1 \mathrm{~min}$ ), but never changed within a block. On $20 \%$ of trials, one of the 12 green dots increased in luminance [from $(0,100,0)$ to $(0,140,0)$ in RGB] for 300 $\mathrm{ms}$, and these brighter dots served as targets in the first two phases of the experiment. Each dot was equally likely to serve as a target. A central fixation cross was present throughout the experiment $\left(0.3^{\circ}\right)$ and subjects were trained to avoid tracking the dots with their eyes. All trials containing a bright dot target were excluded from EEG/ERP analyses.

The design of this distracter stimulus marked two improvements over the distracter stimuli used in Pitts et al. (2012). First, tighter control over spatial attention was achieved by spatially superimposing the critical stimuli (here, faces) with the distracter stimulus (compared with the peripheral positioning of the distracter stimuli in Pitts et al., 2012). Second, the green dots rotated smoothly and continuously, whereas the line segments abruptly "twitched" between stimulus and ISI configurations, thereby ensuring that the ERPs were driven solely by the line segment orientation/location changes and not by the distracter stimuli. In Pitts et al. (2012), the distracter stimuli twitched in temporal synchrony with the line segment changes, thereby contributing to the ERP signal.

Procedure. The experiment consisted of three phases during which the subjects engaged in two different tasks (see Fig. 1). In the first two phases, subjects performed the distracter "dot task," which required distributed attention across the display to detect when one of 12 rotating green dots became briefly brighter. Subjects pressed a response button with their right index finger whenever they detected a bright dot target. In the third phase of the experiment, subjects were instructed to ignore the rotating dots and perform a "face task" in which they pressed the response button whenever they detected a face that was missing a feature (left eye, right eye, nose, or mouth).

Before EEG recording, subjects practiced the dot task for 5 min and, during this period, no faces were presented. The instructions indicated that purpose of the random lines was to make the task more challenging. Subjects were encouraged to be as accurate as possible in the dot task and to try to "beat the top score" of previous subjects in the experiment (an arbitrary top score was specified). The first phase of the experiment lasted 12 minutes and subjects were given short rest breaks after each minute and a longer break after 6 min.

After the first phase, subjects were given a surprise "awareness assessment." The awareness assessment served two purposes. First, it established which subjects had been inattentionally blind during the first phase and which subjects had spontaneously noticed the faces. Second, the awareness questions and stimulus exemplars served as cues, alerting subjects that meaningful patterns might appear within the line segments, ensuring that all subjects would become aware of the faces during the second phase.

The awareness assessment was based on Pitts et al. (2012) and contained two initial open-ended items, followed by presentations of exam- ple stimuli and foil stimuli along with a five point rating scale. The open ended items included: (1) "Describe (or draw) any patterns you observed in the background lines during the target detection task," and (2) "Some participants were randomly assigned to conditions in which the line segments in the background occasionally formed coherent patterns. Did you see any coherent patterns?" Regardless of subjects' responses to these items, five examples of plausible background configurations were then presented: the face stimulus that appeared throughout the study, along with four other line drawings of objects that never actually appeared during the experiment (a house, a violin, a flower, a light bulb, and a car). For each object exemplar, subjects were instructed to rate their confidence in having seen the object during the experiment on a $1-5$ scale $(1=$ very confident I did not see it; $2=$ confident I did not see it; $3=$ uncertain; $4=$ confident I saw it; $5=$ very confident I saw it); to estimate how frequently they had noticed each object $(1=$ never; $2=<10$ times; $3=$ $10-50$ times; $4=50-100$ times; $5=>100$ times); and to indicate when they had first noticed the object $(1=$ training; $2=$ a previous phase; $3=$ first half of this phase; $4=$ second half of this phase; $5=$ never ).

After completing the awareness assessment, subjects were instructed to "keep performing the same dot task again" and were not informed about the presence of faces. The stimuli and task in the second phase of the experiment were identical to the first phase. After the second phase, the same awareness assessment was administered again. Before the third and final phase, participants were instructed to ignore the rotating green dots and to perform a face discrimination task in which they were to respond whenever they detected a face with a missing feature. Before EEG recording of the third phase, subjects were given 2-3 min of practice on the face task. The stimuli presented during the third phase were identical to the two previous phases, with the only difference being the change of task.

Data analysis. EEG data were preprocessed using a combination of BrainVision Analyzer 2.0 (Brain Products), EEGLAB (Delorme and Makeig, 2004), and ERPLAB (Lopez-Calderon and Luck, 2014). EEG signals were time locked to the line segment orientation/location changes and rereferenced to the average of all channels. The left and right horizontal EOG channels were rereferenced as a bipolar pair. Individual electrodes showing extended periods of noise in the raw EEG were removed and replaced by interpolated signals from surrounding channels using topographic spherical splines (channels included in statistical analyses were not interpolated). Trials containing artifacts (e.g., blinks, eye movements, muscle noise) were detected and rejected semiautomatically (on a subject-by-subject basis) using peak-to-peak amplitude thresholds with starting values of $50 \mu \mathrm{V}$ for eye movements, $100 \mu \mathrm{V}$ for blinks, and 200 $\mu \mathrm{V}$ for other artifacts. On average, $14 \%$ of trials were excluded due to button presses and artifacts. All conditions used for statistical analyses had at least 100 trials per condition per subject, with an average of 146 trials for face stimuli and 256 trials for random stimuli. Averaged ERPs were baseline corrected from -100 to $0 \mathrm{~ms}$ and low-pass filtered at $30 \mathrm{~Hz}$ for statistical analyses and at $15 \mathrm{~Hz}$ for visualization purposes.

The time windows and electrode locations for statistical analyses were chosen based on a priori hypotheses (Rossion and Jacques, 2011; Pitts et al., 2012; Pitts et al., 2014a) and fine-tuned using data orthogonal to the statistical comparisons between conditions (peak amplitudes and scalp distributions in the grand-averaged data averaged across all conditions). Difference waves (face minus random control stimuli) were computed within each phase of the experiment to eliminate confounding factors due to repeated exposure to the stimuli across experimental phases (the order of which cannot be counterbalanced due to the nature of the inattentional blindness effect). Difference amplitudes were averaged across electrode clusters and entered into ANOVAs with the within-subjects factor of phase $(1,2,3)$ and the between-subjects factor of group (inattentionally blind, spontaneous noticers). For all components except the $\mathrm{P} 3 \mathrm{~b}$, an additional within-subjects factor hemisphere (left, right) was also included. Main effects and interactions were considered significant if $p<$ 0.05 . The main purpose of these ANOVAs was to test for relative amplitude differences across phases and groups. Because one of our main questions was whether the brain differentiates between face and nonface stimuli during inattentional blindness, we also conducted unidirectional $t$ tests against zero for each experimental phase and group of subjects 
separately and adopted an $\alpha$ threshold of $p<0.0083$ to correct for multiple comparisons.

\section{Results}

\section{Behavioral results}

Awareness assessments

Subjects were split into two groups (inattentionally blind vs noticers) based on their responses to the awareness assessment given after Phase 1. Subjects who described seeing a face in response to the open-ended questions or who indicated a confidence level $>3$ ("uncertain") after seeing the face stimulus exemplar were considered to be aware of the faces during the first phase. Fifteen of the 30 subjects entered into the analysis fell into this group of spontaneous "noticers" during the first phase. Nine of the noticers rated the frequency of having noticed the faces as 4 of 5 (50100 times). Four subjects rated the frequency as a 5 of $5(100+$ times) and the remaining two subjects gave frequency ratings of 3 (10-50 times).

The remaining 15 subjects provided no indication that they had noticed the faces on the open-ended questions and reported confidence levels of 3 ("uncertain") or below for the face stimulus and were thus considered inattentionally blind during the first phase. One subject reported noticing faces specifically in the last minute of Phase 1 (in which $\sim 18$ of 216 intact faces were presented). Due to this late stage of noticing, this subject was included in the "inattentionally blind" group and data from this last minute of trials were excluded. No subjects reported confidence levels $>3$ ("uncertain") for any of the foil stimuli.

After the second phase, all subjects from both groups reported being "very confident" ( 5 on the scale) that they had seen faces during the second phase and all but one subject rated the frequency of noticing faces as 4 or higher (the remaining subject rated the frequency as a 3). After Phase 2, many subjects who were inattentionally blind in Phase 1 voluntarily reported experiences such as, "I can't stop noticing the faces now that I know they are there.” The awareness assessment results, along with these spontaneous reports, confirmed that the intervening questions served as a cue for noticing the faces in the second phase of the experiment.

\section{Task performance}

ANOVA with the factors phase $(1,2)$ and group (inattentionally blind, noticers) were conducted to determine whether noticing faces influenced subjects' ability to perform the distracter dot task. For $d^{\prime}$, there were no main effects of phase or group and no interaction between the two. ANOVA for reaction times (bright dot detection) showed that there was a main effect of phase $\left(F_{(1,28)}=6.90, p=\right.$ $0.013)$, with faster reaction times for both groups in the second phase. There were no other main or interaction effects for reaction times. Together, these results suggest that noticing the taskirrelevant faces did not substantially alter subjects' ability to perform the distracter task.

ANOVA including all three phases were conducted to determine whether the face task differed in difficulty from the dot task. For $d^{\prime}$, there was main effect of phase $\left(F_{(2,56)}=32.24, p<0.0001\right)$, with no other main effects or interactions. Follow-up comparisons revealed that $d^{\prime}$ for the face task $($ mean $=2.24$; SEM $=0.11$ ) was lower than for the dot task [(Phase $1=3.05$ (SEM 0.13); Phase $2=3.13$ (SEM $0.09)]$ during the first $\left(F_{(1,28)}=67.72, p<0.0001\right)$ and second $\left(F_{(1,28)}=84.88, p<0.0001\right)$ phase]. ANOVA for reaction times across all three phases revealed a main effect of phase $\left(F_{(2,56)}=69.75\right.$, $p<0.0001)$, with no group or interaction effects. Reaction times in the third phase $[$ mean RT $=658 \mathrm{~ms}($ SEM $11 \mathrm{~ms})]$ were slower than
Table 1. Mean ERP difference amplitudes (face - random) and SEM for bilateral electrode clusters with unidirectional $t$ test results

\begin{tabular}{lll}
\hline & N170 (180-220 ms) & \\
\cline { 2 - 3 } & Mean (SEM) & $t_{(14)}$ \\
\hline Phase 1 & $-0.19(0.12)$ & -1.57 \\
IB & $-1.65(0.28)$ & $-5.90^{*}$ \\
$\quad$ Noticers & & \\
Phase 2 & $-0.88(0.22)$ & $-4.01^{*}$ \\
$\quad$ IB & $-2.05(0.24)$ & $-8.51^{*}$ \\
$\quad$ Noticers & & \\
Phase 3 & $-2.57(0.39)$ & $-6.59^{*}$ \\
IB & $-3.73(0.37)$ & $-9.96^{*}$ \\
$\quad$ Noticers & &
\end{tabular}

the first phase [ $573 \mathrm{~ms}$ (SEM $\left.10 \mathrm{~ms}), F_{(1,28)}=27.47, p<0.0001\right]$ and the second phase [561 ms $\left.(10 \mathrm{~ms}), F_{(1,28)}=49.48, p<0.0001\right]$. Hit rates (and false alarm rates) for phases 1,2 , and 3 were $74 \%$ (SEM $1.6 \%$ ), $72 \%$ (SEM 1.0\%), and 67\% (SEM 4.7\%), respectively. These results suggest that the face task was slightly more difficult than the dot task.

\section{EEG results}

N170

In the average of all groups, conditions, and stimuli, the maximal window for the N170 was found to be between 180 and $220 \mathrm{~ms}$, at a bilateral cluster of posterior inferior electrodes $(\mathrm{O} 1, \mathrm{O} 2, \mathrm{PO} 7, \mathrm{PO}$, T5, T6, O9, O10, PO9, PO10, P9, P10). An ANOVA exploring mean amplitudes of the N170 by group (inattentionally blind, noticers), phase $(1,2,3)$, and hemisphere (left, right) revealed significant main effects of group $\left(F_{(1,28)}=16.66, p=0.0003\right.$, phase, $F_{(2,56)}=53.66$, $p<0.0001)$ and hemisphere $\left(F_{(1,28)}=19.14, p=0.0002\right)$, as well as an interaction between phase and hemisphere $\left(F_{(2,56)}=13.73, p<\right.$ $0.0001)$. A series of unidirectional $t$ tests was run to further explore the main effects and interaction. Table 1 presents mean amplitudes for each condition along with the $t$ tests results. During Phase 1 , the N170 was not significant in inattentionally blind subjects, whereas the noticers showed a significant N170. In the second phase, the N170 was significant for both groups of subjects. In Phase 3, N170 amplitudes were again significant for both groups of subjects and were $\sim 1.7 \mu \mathrm{V}$ larger compared with Phase 2 . Grand-averaged ERPs, difference waves, and difference topographies for each phase and each group of subjects are provided in Figures 2 and 3.

\section{VAN}

An additional posterior negativity was evident subsequent to the N170, between 265 and 305 ms, at the same bilateral cluster of posterior electrodes. In an ANOVA including group, hemisphere, and phase, both hemisphere and phase reached the criterion for significance (group, $F_{(1,28)}=3.91, p=0.058$; hemisphere, $F_{(1,28)}=5.93$, $p=0.022$; phase, $\left.F_{(1,28)}=83.94, p<0.0001\right)$. There was also a significant interaction between phase and hemisphere $\left(F_{(2,56)}=\right.$ 16.80, $p<0.0001)$. Follow-up $t$ tests confirmed that, in the first phase, when the inattentionally blind group was unaware of the faces, the VAN was not significant. The noticers, however, showed a significant VAN during the first phase. During the second phase, when all subjects were aware of the faces, both groups showed a significant VAN. During the third phase, the VAN was significant in both groups and showed an increased magnitude compared with Phase 2 (Table 2).

SN

The selection negativity (Harter and Aine, 1984; Hillyard and Anllo-Vento, 1998) was measured during a time window 375- 
ERPs

Inattentionally Blind

Phase 1 (unaware)

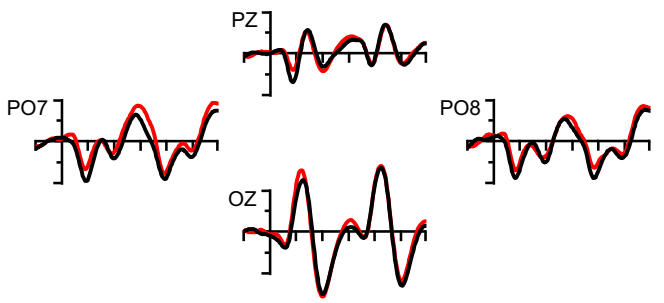

Phase 2 (aware)

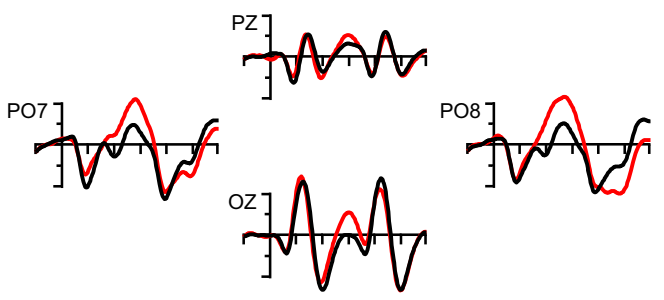

Phase 3 (aware + task-relevant)
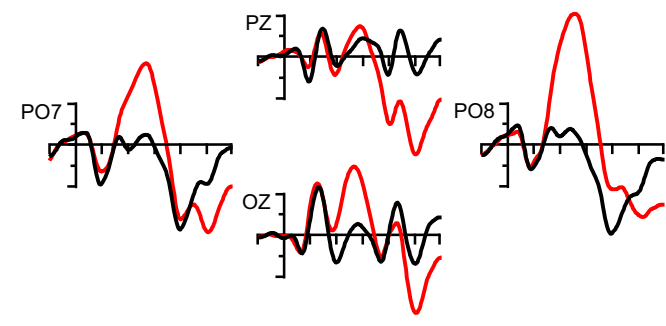

Noticers

Phase 1 (aware)

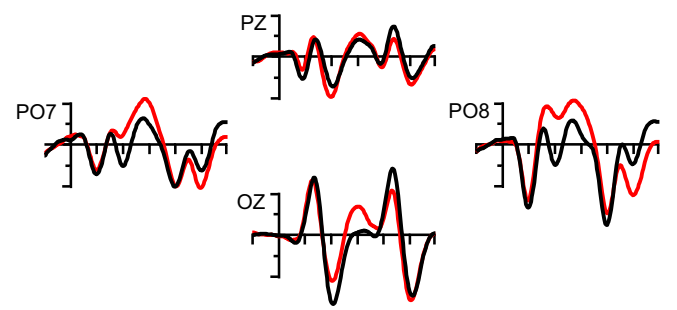

Phase 2 (aware)

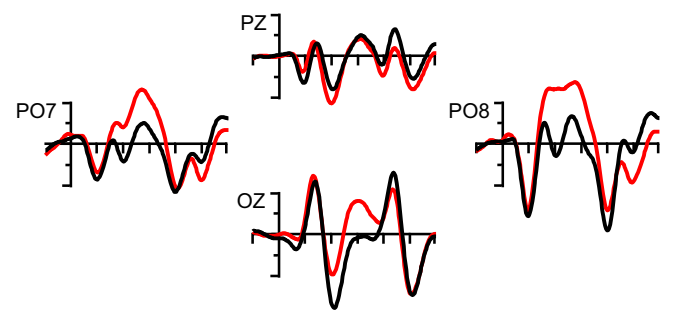

Phase 3 (aware + task-relevant)

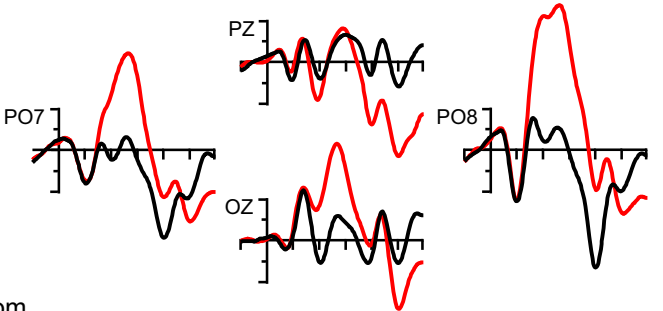

Difference Waves

(face - random)

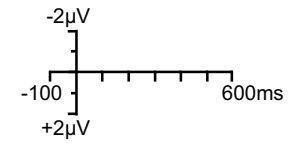

Inattentionally Blind
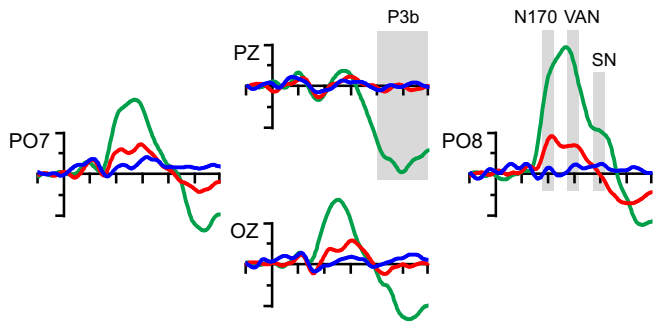

Noticers
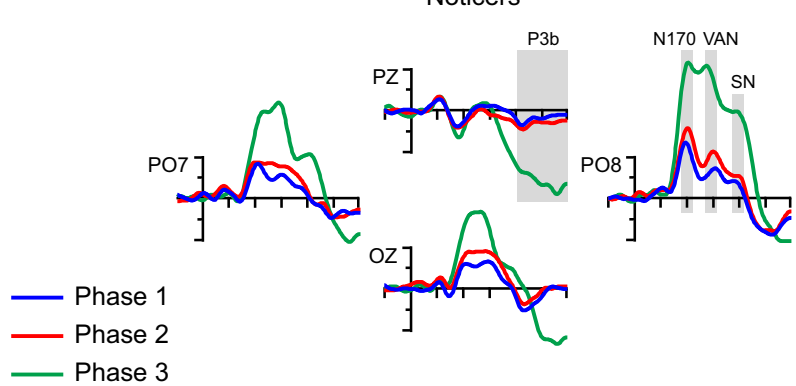

Figure 2. Grand-averaged ERPs elicited by face (red) and random (black) stimuli at representative parietal and occipital electrode sites for the inattentionally blind group of subjects (left) and noticer group of subjects (right) across the three phases of the experiment (top to bottom). The bottom panel plots grand-averaged difference waves (face ERPs - random ERPs) for each of the three phases (blue, red, green) at the same electrode sites. Time windows for the analysis of the N170, VAN, SN, and P3b are labeled and highlighted with gray boxes in the difference wave plots.

$415 \mathrm{~ms}$ after the stimulus, at a bilateral occipital-parietal cluster of electrodes (PO7, T5, O9, PO9, P9, PO11, P11, PO8, T6, PO10, $\mathrm{P} 10, \mathrm{PO} 12, \mathrm{P} 12)$. This third negative component can be visualized in the difference wave traces for Phase 3 (Fig. 2). In an ANOVA including group, phase, and hemisphere, main effects of group $\left(F_{(1,28)}=4.43 ; p=0.044\right)$, phase $\left(F_{(2,56)}=15.66 ; p=\right.$ $0.00015)$, and hemisphere $\left(F_{(1,28)}=11.76 ; p=0.0019\right)$ were significant. There was also a significant phase by hemisphere interaction, $\left(F_{(2,56)}=8.37 ; p=0.0029\right)$. Unidirectional $t$ tests con- firmed that neither group of subjects demonstrated a significant $\mathrm{SN}$ in Phases 1 and 2. The noticers showed a significant SN during the third phase, whereas the $\mathrm{SN}$ for the inattentionally blind group approached significance in Phase 3 (Table 3 ).

$P 3 b$

Mean ERP amplitudes during a 400-600 ms window at centralparietal electrode sites $(\mathrm{Cz}, \mathrm{CPz}, \mathrm{Pz}, \mathrm{P} 1, \mathrm{P} 2, \mathrm{PO} 3, \mathrm{PO} 4, \mathrm{POz}, \mathrm{Oz})$ were used to assess the $\mathrm{P} 3 \mathrm{~b}$ component. An ANOVA explored the 


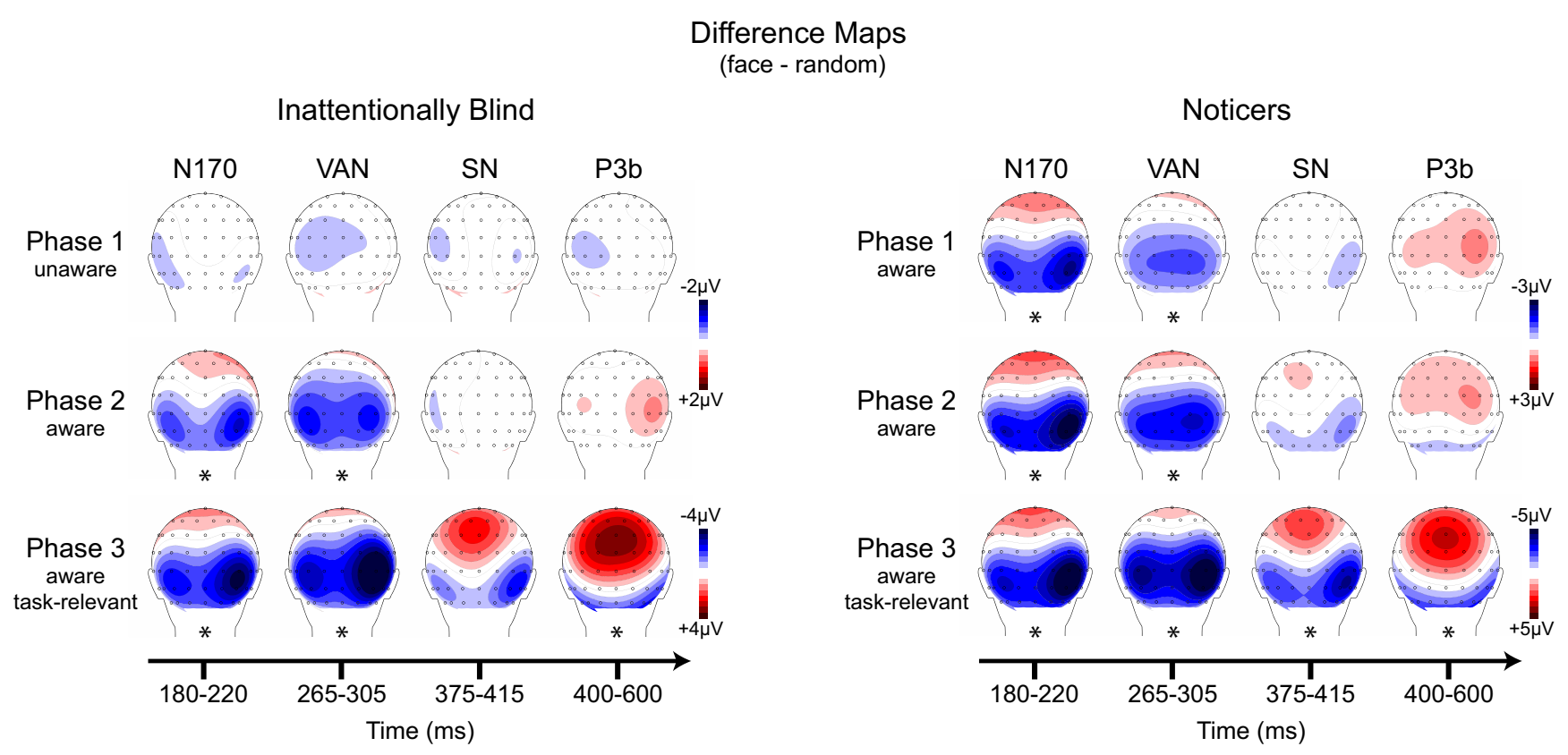

Figure 3. Difference-wave scalp topographies (face - random; back view of head) for the four components of interest (each column) across the three phases of the experiment (each row) for the inattentionally blind group (left) and noticer group of subjects (right). Asterisks under the scalp maps indicate whether the difference was significant $(p<0.0083)$ for the relevant electrode cluster during the analyzed time window.

Table 2. Mean ERP difference amplitudes (face - random) and SEM for bilateral electrode clusters with unidirectional $t$ test results

\begin{tabular}{lll}
\hline & \multicolumn{1}{l}{ VAN (265-305 ms) } & \\
\cline { 2 - 3 } & Mean (SEM) & $t_{(14)}$ \\
\hline Phase 1 & $-0.20(0.13)$ & -1.57 \\
IB & $-0.97(0.27)$ & $-3.63^{*}$ \\
$\quad$ Noticers & & \\
Phase 2 & $-0.94(0.22)$ & $-4.36^{*}$ \\
$\quad$ IB & $-1.54(0.25)$ & $-6.25^{*}$ \\
$\quad$ Noticers & & \\
Phase 3 & $-3.18(0.53)$ & $-5.96^{*}$ \\
IB & $-3.95(0.46)$ & $-8.64^{*}$ \\
$\quad$ Noticers & &
\end{tabular}

effects of group and phase, revealing a significant effect of phase $\left(F_{(2,56)}=69.63 ; p<0.0001\right)$, but not group $\left(F_{(1,28)}=1.26 ; p=\right.$ $0.27)$, and no interaction between the two. Unidirectional $t$ tests on the differences between face and random stimuli in each phase helped to determine the conditions in which the $\mathrm{P} 3 \mathrm{~b}$ was present (Table 4). In Phases 1 and 2, neither group of subjects showed a significant P3b, despite both groups being aware of the faces in Phase 2. In the third phase, when the faces were task relevant, the $\mathrm{P} 3 \mathrm{~b}$ was robust and significant in both groups of subjects.

\section{Discussion}

The N170 component (180-220 ms) was absent during inattentional blindness, present when subjects consciously perceived task-irrelevant face stimuli, and significantly enhanced when faces became relevant to the discrimination task. The VAN (265$305 \mathrm{~ms}$ ) followed this same pattern, appearing whenever subjects were aware of the faces regardless of task relevance and showing an increase in amplitude during task-relevant conditions. The SN (375-415 ms) and P3b (400-600 ms) were evident only when the faces were consciously perceived and relevant to the discrimination task.

\section{N170}

Previous studies have examined the relationship between the $\mathrm{N} 170$ and conscious face perception and results have been mixed. Some studies suggest an N170 even in the absence of awareness (Sterzer et al., 2009; Harris et al., 2013; Suzuki and Noguchi, 2013), whereas others report an N170 only during conscious face perception (Reiss and Hoffman, 2007; Fisch et al., 2009; Babiloni et al., 2010; Harris and Waldorff, 2011; Rodríguez et al., 2012; Navajas et al., 2013; Sandberg et al., 2013). The studies reporting an N170 in unconscious conditions used either the attentional blink paradigm (Harris et al., 2013) or continuous flash suppression (CFS; Sterzer et al., 2009; Suzuki and Noguchi, 2013) to manipulate awareness.

In a recent review, Axelrod et al. (2015) posited that the mixed results may be explained by paradigmatic differences, specifically, whether attention is manipulated and whether stimuli are presented monocularly or dichotically. The present results, along with those of Harris et al. (2013) and Sandberg et al. (2013), however, argue against this view. Attention was manipulated in both the present study and in Harris et al. (2013), but the N170 was absent in one case and present in the other. Stimuli were presented monocularly in the present study and binocularly in Sandberg et al. (2013), but the N170 was absent during unaware conditions in both studies.

The key factor that determines whether early face-specific processing can occur unconsciously may be related to the presence or absence of recurrent processing (Lamme and Roelfsema, 2000; Lamme, 2006, 2010). In the attentional blink and CFS, all stimuli of interest are spatially attended, expected, task-relevant targets, so early local recurrency may be preserved even when conscious perception is blocked at a later stage. In the current experiment, the unaware condition consisted of completely unattended, unexpected, task-irrelevant nontarget faces and the lack of top-down input on stimulus processing is likely to be a primary cause of inattentional blindness. If the $\mathrm{N} 170$ reflects an early stage of top-down attention to faces subserved by local re- 
Table 3. Mean ERP difference amplitudes (face - random) and SEM for bilateral electrode clusters with unidirectional $t$ test results

\begin{tabular}{|c|c|c|}
\hline & \multicolumn{2}{|c|}{ SN (375- $415 \mathrm{~ms})$} \\
\hline & Mean (SEM) & $t_{(14)}$ \\
\hline \multicolumn{3}{|l|}{ Phase 1} \\
\hline IB & $-0.08(0.15)$ & -0.73 \\
\hline Noticers & $-0.33(0.22)$ & -1.50 \\
\hline \multicolumn{3}{|l|}{ Phase 2} \\
\hline IB & $-0.04(0.17)$ & -0.22 \\
\hline Noticers & $-0.71(0.24)$ & -2.99 \\
\hline \multicolumn{3}{|l|}{ Phase 3} \\
\hline IB & $-1.35(0.60)$ & -2.23 \\
\hline Noticers & $-2.54(0.53)$ & $-4.78^{*}$ \\
\hline
\end{tabular}

Table 4. Mean ERP difference amplitudes (face - random) and SEM for a central occipital electrode cluster with unidirectional $t$ test results

\begin{tabular}{lrr}
\hline & P3b $(400-600 \mathrm{~ms})$ & \multicolumn{1}{c}{$t_{(14)}$} \\
\cline { 2 - 3 } & Mean (SEM) & \\
\hline Phase 1 & $-0.08(0.11)$ & -0.73 \\
IB & $0.36(0.21)$ & 1.73 \\
Noticers & & \\
Phase 2 & $0.13(0.17)$ & 0.78 \\
IB & $0.57(0.27)$ & 2.13 \\
Noticers & & \\
Phase 3 & $2.78(0.29)$ & $9.50^{*}$ \\
IB & $2.67(0.39)$ & $6.78^{*}$ \\
Noticers & & \\
\hline${ }^{*} p<0.0083$. & &
\end{tabular}

currency in the ventral stream, it makes sense that it was present in attentional blink and CFS studies (in which some varieties of top-down attention were present) but absent during inattentional blindness (in which top-down attention was absent). The reason that backward masking studies do not find an N170 in unaware but attended and task-relevant conditions (Rodríguez et al., 2012; Harris and Waldorff, 2011) may be that short masking intervals (typically $16-50 \mathrm{~ms}$ ) interfere with this initial stage of local recurrent processing (Fahrenfort et al., 2007, 2008). In other words, recurrent processing may survive the attentional blink and CFS while being disrupted by inattention, binocular rivalry, and backward masking (Martínez et al., 1999; Lamme et al., 2002; Boehler et al., 2009; Pitts et al., 2010). This hypothesis links the N170 with a particular mode of cortical processing (local recurrancy) and with early stages of object-based attention. These physiological/functional precursors are likely necessary (but not sufficient) for perceptual awareness.

Nevertheless, previous studies have reported an N170 even in unattended conditions, suggesting a preattentive feedforward neural mechanism (Cauquil et al., 2000; Furey et al., 2006). Here, it is important to distinguish inattention from unattended conditions. Inattention refers to the complete absence of attention, whereas unattended conditions typically refer to situations in which a stimulus is ignored because it is irrelevant to the task (Schankin and Wascher, 2008). In unattended conditions, stimuli can be initially attended, perceived, and then ignored for task purposes. In the present study, the three phases of the experiment could have been labeled "inattention," "partial attention," and "full attention," respectively. In this sense, it appears that at least a minimal amount of attention to faces is required for elicitation of the N170 (see also Jacques and Rossion, 2007; Mohamed et al., 2009; Sreenivasan et al., 2009).

A second factor worth considering is that the current study used line drawings of faces, which contain only high spatial fre- quencies, whereas previous studies used photographs of faces (Sterzer et al., 2009; Harris et al., 2013). It is possible that unconscious face processing relies exclusively on low spatial frequency information, explaining the absence of an N170 in the unaware condition of the current study (see also de Gardelle and Kouider, 2010). Future studies could explore this alternative by presenting faces containing low spatial frequencies during inattentional blindness.

\section{VAN}

Results from the current study show clearly that the N170 and VAN were absent in the unaware condition and present in the aware conditions regardless of task relevance. As explained above, previous studies reported the presence of an N170 in unaware conditions. Therefore, it is unlikely that both the N170 and the VAN are neural signatures of conscious face perception despite their comodulation with awareness in the present study. One interpretation is that the N170 reflects attention to faces, a necessary precursor to awareness, whereas the VAN indexes perceptual awareness. Indeed, previous studies have reported attention-based modulations of the N170 (Eimer, 2000; Downing et al., 2001; Jacques and Rossion, 2007; Mohamed et al., 2009; Sreenivasan et al., 2009) and the VAN has been identified in a wide variety of experiments (Koivisto and Revonsuo, 2003, 2007, 2008, 2010; Koivisto et al., 2005, 2006, 2008; Busch et al., 2010a, 2010b; Harris et al., 2013; Sandberg et al., 2013).

Alternatively, both the N170 and the VAN may index different stages/types of object-based attention, both of which are necessary precursors for conscious face perception, but neither of which reflects the neural processes underlying conscious perception per se. The present data may appear to favor this view because of the amplitude enhancements of both the N170 and VAN in the task-relevant condition. If either component reflected perceptual awareness, which is often assumed to be an all-or-none (as opposed to graded) phenomenon (Dehaene and Changeux, 2011), then why should the amplitude of an ERP signature of awareness vary between two different "aware" conditions? We have argued previously that these amplitude differences may be deceiving because lower amplitudes in the averaged ERP might reflect increased temporal variability from trial to trial instead of a consistent difference in response magnitude (Pitts et al., 2014b). The difference waves (Fig. 2) indeed suggest sharper, shorter duration peaks for the N170 and VAN components in the taskrelevant condition compared with lower amplitude, temporally broader peaks in the aware (task-irrelevant) condition. A recent study that examined single-trial temporal jitter in the N170 component supports this view (Navajas et al., 2013).

Based on the current results, as well as a number of previous studies, we advocate for a working hypothesis in which the N170 depends critically on early top-down attention to faces (but may be elicited in the absence of awareness under certain conditions), whereas the VAN is either an ERP signature of conscious perception or a product of the interaction between a particular type of object-based attention and higher-level perceptual representations (see Cohen and Dennett, 2011; Graziano and Kastner, 2011 for similar views). This specific type of interaction may be critical for the integration of sensory information thought to underlie our moment-to-moment conscious experience (Tononi, 2004; Fahrenfort et al., 2012; Tononi, 2012; Mudrik et al., 2014). 


\section{Postperceptual processing}

By using a paradigm that allowed for "aware" versus "unaware" contrasts in task-irrelevant situations, the present study helps to exclude a number of potential neural signatures of conscious perception, most notably the $\mathrm{SN}$ and $\mathrm{P} 3 \mathrm{~b}$. A leading theory concerning the neural basis of consciousness, the global neuronal workspace theory (GNWT), posits that the late P3b wave $(>300$ $\mathrm{ms}$ ) is a signature of global workspace activation (Dehaene and Changeux, 2011; Dehaene, 2014). The current results, along with a number of previous studies (Aru et al., 2012b; Pitts et al., 2012; Sandberg et al., 2013; Pitts et al., 2014a; Pitts et al., 2014b), argue against the view that the $\mathrm{P} 3 \mathrm{~b}$ is a neural marker of conscious perception, contradicting a key hypothesis put forward by GNWT. Future fMRI or intracranial EEG studies should consider adopting paradigms that can separate postperceptual from awareness-related activity (such as the paradigm used here) to test the remaining predictions of the GNWT.

\section{Notes}

Supplemental material for this article is available at https://www.youtube.com/watch? $\mathrm{v}=\mathrm{aWsfO} 2 \mathrm{FNlp} 0$. This video demonstrates how the stimuli appeared to subjects across all three phases of the experiment. Please see the Materials and Methods section for details. This material has not been peer reviewed.

\section{References}

Aru J, Bachmann T, Singer W, Melloni L (2012a) Distilling the neural correlates of consciousness. Neurosci Biobehav Rev 36:737-746. CrossRef Medline

Aru J, Axmacher N, Do Lam AT, Fell J, Elger CE, Singer W, Melloni L (2012b) Local category-specific gamma band responses in the visual cortex do not reflect conscious perception. J Neurosci 32:14909-14914. CrossRef Medline

Axelrod V, Bar M, Rees G (2015) Exploring the unconscious using faces. Trends Cogn Sci 19:35-45. CrossRef Medline

Babiloni C, Vecchio F, Buffo P, Buttiglione M, Cibelli G, Rossini PM (2010) Cortical responses to consciousness of schematic emotional facial expressions: a high-resolution EEG study. Hum Brain Mapp 31:1556-1569. CrossRef Medline

Bentin S, Allison T, Puce A, Perez E, McCarthy G (1996) Electrophysiological studies of face perception in humans. J Cogn Neurosci 8:551-565. CrossRef Medline

Boehler CN, Tsotsos JK, Schoenfeld MA, Heinze HJ, Hopf JM (2009) The center-surround profile of the focus of attention arises from recurrent processing in visual cortex. Cereb Cortex 19:982-991. CrossRef Medline

Busch NA, Dürschmid S, Herrmann CS (2010a) ERP effects of change localization, change identification, and change blindness. Neuroreport 21: 371-375. CrossRef Medline

Busch NA, Fründ I, Herrmann CS (2010b) Electrophysiological evidence for different types of change detection and change blindness. J Cogn Neurosci 22:1852-1869. CrossRef Medline

Cauquil AS, Edmonds GE, Taylor MJ (2000) Is the face-sensitive N170 the only ERP not affected by selective attention? Neuroreport 11:2167-2171. CrossRef Medline

Cohen MA, Dennett DC (2011) Consciousness cannot be separated from function. Trends Cogn Sci 15:358-364. CrossRef Medline

Crick F, Koch C (2003) A framework for consciousness. Nat Neurosci 6:119-126. CrossRef Medline

de Gardelle V, Kouider S (2010) How spatial frequencies and visual awareness interact during face processing. Psychol Sci 21:58-66. CrossRef Medline

de Graaf TA, Hsieh PJ, Sack AT (2012) The 'correlates' in neural correlates of consciousness. Neurosci Biobehav Rev 36:191-197. CrossRef Medline

Dehaene S (2014) Consciousness and the brain: Deciphering how the brain codes our thoughts. New York: Penguin Group.

Dehaene S, Changeux JP (2011) Experimental and theoretical approaches to conscious processing. Neuron 70:200-227. CrossRef Medline

Delorme A, Makeig S (2004) EEGLAB: an open source toolbox for analysis of single-trial EEG dynamics including independent component analysis. J Neurosci Methods 134:9-21. CrossRef Medline

Downing P, Liu J, Kanwisher N (2001) Testing cognitive models of visual attention with fMRI and MEG. Neuropsychologia 39:1329-1342. CrossRef Medline

Eimer M (2000) Effects of face inversion on the structural encoding and recognition of faces: evidence from event-related brain potentials. Brain Res Cogn Brain Res 10:145-158. CrossRef Medline

Fahrenfort JJ, Scholte HS, Lamme VA (2007) Masking disrupts reentrant processing in human visual cortex. J Cogn Neurosci 19:1488-1497. CrossRef Medline

Fahrenfort JJ, Snijders TM, Heinen K, van Gaal S, Scholte HS, Lamme VA (2012) Neuronal integration in visual cortex elevates face category tuning to conscious face perception. Proc Natl Acad Sci U S A 109:2150421509. CrossRef Medline

Fahrenfort JJ, Scholte HS, Lamme VA (2008) The spatiotemporal profile of cortical processing leading up to visual perception. J Vis 8:12.1-12. Medline

Fisch L, Privman E, Ramot M, Harel M, Nir Y, Kipervasser S, Andelman F, Neufeld MY, Kramer U, Fried I, Malach R (2009) Neural "ignition": enhanced activation linked to perceptual awareness in human ventral stream visual cortex. Neuron 64:562-574. CrossRef Medline

Furey ML, Tanskanen T, Beauchamp MS, Avikainen S, Uutela K, Hari R, Haxby JV (2006) Dissociation of face-selective cortical responses by attention. Proc Natl Acad Sci U S A 103:1065-1070. CrossRef Medline

Graziano MS, Kastner S (2011) Human consciousness and its relationship to social neuroscience: a novel hypothesis. Cogn Neurosci 2:98-113. CrossRef Medline

Harris JA1, Wu CT, Woldorff MG (2011) Sandwich masking eliminates both visual awareness of faces and face-specific brain activity through a feedforward mechanism. J Vis 11:pii:3. CrossRef Medline

Harris JA, McMahon AR, Woldorff MG (2013) Disruption of visual awareness during the attentional blink is reflected by selective disruption of late-stage neural processing. J Cogn Neurosci 25:1863-1874. CrossRef Medline

Harter M, Aine C (1984) Brain mechanisms of visual selective attention. In: Varieties of attention (Parasuraman P, Davis D, editors). New York: Academic, pp 293-321.

Hillyard S, Anllo-Vento L (1998) Event-related brain potentials in the study of visual selective attention. Proc Natl Acad Sci U S A 95(3), p. 781-7.

Jacques C, Rossion B (2007) Electrophysiological evidence for temporal dissociation between spatial attention and sensory competition during human face processing. Cereb Cortex 17:1055-1065. Medline

Kim CY, Blake R (2005) Psychophysical magic: rendering the visible 'invisible'. Trends Cogn Sci 9(8), 381-388. CrossRef

Koivisto M, Revonsuo A (2003) An ERP study of change detection, change blindness, and visual awareness. Psychophysiology 40:423-429. CrossRef Medline

Koivisto M, Revonsuo A (2007) Electrophysiological correlates of visual consciousness and selective attention. Neuroreport 18:753-756. CrossRef Medline

Koivisto M, Revonsuo A (2008) The role of selective attention in visual awareness of stimulus features: electrophysiological studies. Cogn Affect Behav Neurosci 8:195-210. CrossRef Medline

Koivisto M, Revonsuo A (2010) Event-related brain potential correlates of visual awareness. Neurosci Biobehav Rev 34:922-934. CrossRef Medline

Koivisto M, Revonsuo A, Salminen N (2005) Independence of visual awareness from attention at early processing stages. Neuroreport 16:817-821. CrossRef Medline

Koivisto M, Revonsuo A, Lehtonen M (2006) Independence of visual awareness from the scope of attention: an electrophysiological study. Cereb Cortex 16:415-424. Medline

Koivisto M, Lähteenmäki M, Sørensen TA, Vangkilde S, Overgaard M, Revonsuo A (2008) The earliest electrophysiological correlate of visual awareness? Brain Cogn 66:91-103. CrossRef Medline

Lamme VA (2006) Towards a true neural stance on consciousness. Trends Cogn Sci 10:494-501. CrossRef Medline

Lamme VA (2010) How neuroscience will change our view on consciousness. Cogn Neurosci 1:204-220. CrossRef Medline

Lamme VA, Roelfsema PR (2000) The distinct modes of vision offered by feedforward and recurrent processing. Trends Neurosci 23:571-579. CrossRef Medline 
Lamme VA, Zipser K, Spekreijse H (2002) Masking interrupts figureground signals in V1. J Cogn Neurosci 14:1044-1053. Medline

Lopez-Calderon J, Luck SJ (2014) ERPLAB: an open-source toolbox for the analysis of event-related potentials. Front Hum Neurosci 8:213. Medline

Mack A, Rock I (1998) Inattentional blindness. Cambridge, MA: MIT.

Martínez A, Anllo-Vento L, Sereno MI, Frank LR, Buxton RB, Dubowitz DJ, Wong EC, Hinrichs H, Heinze HJ, Hillyard SA (1999) Involvement of striate and extrastriate visual cortical areas in spatial attention. Nat Neurosci 2:364-369. CrossRef Medline

Mohamed TN, Neumann MF, Schweinberger SR (2009) Perceptual load manipulation reveals sensitivity of the face-selective N170 to attention. Neuroreport 20:782-787. CrossRef Medline

Mudrik L, Faivre N, Koch C (2014) Information integration without awareness. Trends Cogn Sci 18:488-496. CrossRef Medline

Navajas J, Ahmadi M, Quiroga RQ (2013) Uncovering the mechanisms of conscious face perception: a single-trial study of the 170 responses. J Neurosci 33(4): 1337-1343. CrossRef

Pitts MA, Martínez A, Hillyard SA (2012) Visual processing of contour patterns under conditions of inattentional blindness. J Cogn Neurosci 24: 287-303. CrossRef Medline

Pitts MA, Padwal J, Fennelly D, Martínez A, Hillyard SA (2014a) Gamma band activity and the P3 reflect post-perceptual processes, not visual awareness. Neuroimage 101:337-350. CrossRef Medline

Pitts MA, Martínez A, Hillyard SA (2010) When and where is binocular rivalry resolved in the visual cortex? J Vis 10:pii:25. CrossRef Medline

Pitts MA, Metzler S, Hillyard SA (2014b) Isolating neural correlates of conscious perception from neural correlates of reporting one's perception. Front Psychol 5:1078, 1-16. Medline

Railo H, Koivisto M, Revonsuo A (2011) Tracking the processes behind conscious perception: A review of event-related potential correlates of visual consciousness. 20:972-983.

Reiss JE, Hoffman JE (2007) Disruption of early face recognition processes by object substitution masking. Vis Cogn 15:789-798. CrossRef

Rodríguez V, Thompson R, Stokes M, Brett M, Alvarez I, Valdes-Sosa M, Duncan J (2012) Absence of face-specific cortical activity in the com- plete absence of awareness: Converging evidence from functional magnetic resonance imaging and event-related potentials. J Cogn Neurosci 24:396-415. Medline

Rossion B, Jacques C (2011) The N170: Understanding the time course of face perception in the human brain. In: The Oxford handbook of eventrelated potential components (Luck SJ, Kappenman ES, editors). Oxford: OUP, pp 115-141.

Sandberg K, Bahrami B, Kanai R, Barnes GR, Overgaard M, Rees G (2013) Early visual responses predict conscious face perception within and between subjects during binocular rivalry. J Cogn Neurosci 25:969-985. CrossRef Medline

Schankin A, Wascher E (2008) Unvoluntary attentional capture in change blindness. Psychophysiology 45:742-750. CrossRef Medline Medline

Sergent C, Baillet S, Dehaene S (2005) Timing of the brain events underlying access to consciousness during the attentional blink. Nat Neurosci 8:1391-1400. CrossRef

Simons DJ, Chabris CF (1999) Gorillas in our midst: sustained inattentional blindness for dynamic events. Perception 28:1059-1074. CrossRef Medline

Sreenivasan KK, Goldstein JM, Lustig AG, Rivas LR, Jha AP (2009) Attention to faces modulates early face processing during low but not high face discriminability. Atten Percept Psychophys 71:837-846. CrossRef Medline

Sterzer P, Jalkanen L, Rees G (2009) Electromagnetic responses to invisible face stimuli during binocular suppression. Neuroimage 46:803-808. CrossRef Medline

Suzuki M, Noguchi Y (2013) Reversal of the face-inversion effect in N170 under unconscious visual processing. Neuropsychologia 51:400-409. CrossRef Medline

Tononi G (2004) An information integration theory of consciousness. BMC Neurosci 5:42. CrossRef Medline

Tononi G (2012) Integrated information theory of consciousness: an updated account. Arch Ital Biol 150:293-329. Medline

Zhao C, Seriès P, Hancock PJ, Bednar JA (2011) Similar neural adaptation mechanisms underlying face gender and tilt aftereffects. Vis Res 51:20212030. CrossRef Medline 